\title{
VISCERO-SOMATIC INTEGRATION: NEW THERAPEUTIC PROPOSALS THROUGH INTEGRATED THERMAL CURES (CIT)
}

Barassi Giovanni ${ }^{1}$, Irace Giuseppe ${ }^{2}$, di Iulio Antonella ${ }^{3}$, Di Stefano Giuseppe ${ }^{4}$, Di Simone Edoardo 5 , Mariani Chiara ${ }^{5}$, Supplizi Marco ${ }^{6}$, di Iorio Angelo ${ }^{7}$

${ }^{I}$ PhD, Coordinator of the Physiotherapy Center for Rehabilitation and Reeducation (Ce.Fi.R.R.) venue "G. d'Annunzio University" Chieti-Pescara (IT); CIT Project Coordinator (Integrated Thermal Cares) of Medical Thermal Centre, Castelnuovo della Daunia (FG-IT).

${ }^{2}$ MSc, Water Rehabilitation Laboratory of Ce.Fi.R.R. venue "G. d'Annunzio" University of Chieti-Pescara (ChietiIT); Member of the CIT (Integrated Thermal Cares) Project of the Medical Thermal Center of Castelnuovo della Daunia (FG-IT).

${ }^{3}$ MSc, U.O.C. Thoracic Surgery. "Santo Spirito” Hospital Pescara, ASL Pescara (Italy);

${ }^{4}$ BSc, Member of the CIT (Integrated Thermal Cares) Project of the Medical Thermal Center of Castelnuovo della Daunia (FG-IT).

${ }^{5}$ BSc, Water Rehabilitation Laboratory of Ce.Fi.R.R. venue "G. d'Annuznio University” Chieti-Pescara (IT).

${ }^{6} \mathrm{MSc}$, Coordinator of the Physiotherapy Center for Rehabilitation and Reeducation (Ce.Fi.R.R.) venue "G. d'Annunzio University" Chieti-Pescara (IT).

7Associate Professor Department of Aging Sciences, “G.d'Annunzio” University Chieti-Pescara

KEYWORDS: Hydrotherapy, Neurological Rehabilitation, Physiotherapy, Rehabilitation,

\section{ABSTRACT}

Traditional thermal medicine, gold standard for some pathologies, focuses its therapeutic target mainly on a sectorial level, focusing only on the pathological symptom and neglecting man as a whole.

The importance of the whole, of the phenomena of systemic, viscero-somatic and somato-visceral interrelation, has led to the creation of a new approach called "CTI"-Integrated Thermal Care, which uses all the thermal therapies, integrated and administered according to the individual needs to enhance their therapeutic effect.

235 subjects have received, on average, 40 treatments within about a year. They were treated with hydropinic treatment, inhalation treatments, hydrokinesitherapy, vascular pathways, mud therapy and manual neuromuscular therapy associated with the previous treatments.

The results obtained in all the FIM, VAS, TINETTI, EUROQOL scales are positive and statistically significant, which suggests that a modification of the treatment protocols, which provides for a unique and integrated stimulation, is the new objective of thermal medicine for serious disabilities.

\section{INTRODUCTION}

In the multisystem approach to sensorineural disabilities, it is necessary to consider all the therapeutic possibilities and the multiple comorbidities that may be present in patients suffering from the same pathology.

Awareness of the importance of whole, of individuality, of the systemic interrelation phenomena, of a holistic and non-invasive approach, of the importance of the human and psychological factor in maintaining health and in diseases treatment continues to grow.

Recent biomedical sciences acquisitions have shown that the morbid event is not a localized phenomenon but is the consequence of a general imbalance in which internal and external factors act through the general alteration of complex homeodynamic mechanisms (Jackson, 1990).

The timely and correct framework of visceral and somatic dysfunction in our clinical practice is indispensable considering that the symptom can be an expression of conditions potentially harmful to the patient's health (e.g., myocardial infarction, acute pancreatitis, peritonitis, gastritis, sinusitis). However, this framework is not always easy because, unlike somatic dysfunction, visceral dysfunction has very variable characteristics, both inter-individual and, over time, in the same individual, as well as in relation to the patient's sex and age (Barassi et al., 2018).

In the context of sensorineural disabilities, the clinical picture is often complicated by the presence of concomitant visceral pathologies, which give rise to complex symptomatic and structuralsomatic interactions. The clinical-semeiological peculiarities of visceral and somatic dysfunction are attributable to its complex pathogenesis, different from the pathogenesis of visceral dysfunction. Somatic dysfunction is defined as the expression of a compromised or altered function of the somatic system components (body): skeletal, arthrodial and myofascial structures, and related vascular, lymphatic and neural elements. It is considered as one of the main reversible and functional factors that influence the body economy and the origin of many disorders even in areas distant from the dysfunctional area.

The dysfunctional area normalization is essential to restore normal mobility and the function of the entire musculoskeletal system. Somatic dysfunction can affect an organ or bowel. Myofascial trigger points represent one of the methods for recognizing viscerosomatic dysfunctions and, through manipulative treatment, influence a reconditioning somato-visceral effect. Trigger points tend to manifest themselves as small nodular masses, palpable in soft tissues, which show, at the palpation, a defined pain without 
irradiation. Viscero-somatic reflexes are typically found in positions that are segmentally related to visceral innervation. In addition, they are the manifestation of the sympathetic nervous system dysfunction on lymphatic vascularization linked to segmentation. In the spinal cord and upper centers, the visceral afferent fibers systematically converge with the somatic fibers on the same sensory neurons, viscero-somatic convergence (Laird et al., 2018).

Thermal Medicine is a branch of medicine that uses thermal treatments for therapeutic and rehabilitative purposes. Thermalism, understood as the means, at present, does not seem to be part of a real medical branch, even if the law 833/1978 attributed to thermal medicine an important role for the maintenance of health (Gianfaldoni S. et al 2017).

A crucial point of this discipline is the maintenance of a high level of clinical and scientific research to further study the therapeutic activity of mineral waters even if, to date, many experimental studies have been published attesting to the effectiveness of thermal treatments (Diot, 1995). Castelnuovo della Daunia Terme represents a thermal care center in the Foggia province with a sulphate-alkalineearthy bicarbonate mineral water, bromine-iodine for the presence of bromine and iodine in moderate quantities. The waters are used with the more modern and scientifically proven treatment techniques, for hydropinic therapy, ozonated balneotherapy, mud therapy with matured and macerated mud, obtained from volcanic ash (bentonite), in mineral water; for inhalation treatments (aerosol, hot-humid inhalations, sprays, humage, politzer, insufflations, volumetric and pressometric lung ventilations, swimming pool for mineral water therapy; for the vascular path and at different temperatures with lateral jets of variable height for the whirlpool.

The purpose of this study is to demonstrate the effectiveness of the personalized combination of thermal techniques associated with manual somatic stimulation of myofascial trigger points, with the aim of creating a simultaneous somato-visceral stimulation and vice versa at the same metameric level. (Barassi et al., 2018).

\section{MATERIALS AND METHODS}

The "CTI" Project of Integrated Thermal Care, since the last communication of $03 / 10 / 2017$ by the Department of Rehabilitation of the ASL FG, allows all disabilities (art. 3 paragraph 3 L 104/92) to be treated with this mode, with 20 sessions of repeatable integrated thermal therapies.

The CTI project, necessarily customized and aimed at the maximum recovery of functional skills and secondary and tertiary prevention for the subject, had the purpose of being able to develop different programs over time, adapted to the different phases of recovery, to the personality and motivations of the patient, to the modulation of learning and the progressive functional recovery of the immune, neuroendocrine and neuro-motor system, re-modulating its motor and neurovegetative skills (Barassi et al., 2020).

With this "Proposal for Integrated Thermal Care" neurologicaldisabilities havebeen treated by increasing motor performance with hydrokinesitherapy, improving gastro-intestinal visceral function through hydropinic treatment, improving respiratory function, compromised by postural and neurological alterations, with complete inhalation treatments and normalization of muscle tone with reflex techniques on myofascial trigger points and through localized mud at different temperatures.

The "Integrated Thermal Care proposal" for vascular disabilities was created by exploiting the therapeutic characteristics, in particular of the ozonated vascular path and hydrokinesitherapy, integrating where necessary the use of complete inhalation treatments and localized mud at different temperatures for the treatment of joint dysfunctions and associated postural compensation. Hydrokinesitherapy has proven to be useful for postural rebalancing and muscle function in relation to the peripheral pump effect of the muscle itself.

Really interesting was the approach to cancer survivors, in particular to mastectomized women, through the therapeutic combination of CTI, hydropinic therapies, associated with respiratory rehabilitation, were administered, through the combination of contemporary bronchial stimulation and the somatic stimulation of the muscle structures associated with respiration and postural alterations post-surgery, integrating these viscero-somatic and postural stimulations in thermal water and through the manual treatment of myofascial trigger points in the same aquatic environment (Barassi et al., 2018).

All the patients evaluated received an average of 40 treatments for each over a year (November 2018 / August 2019)

\section{RESULTS}

Over 500 people were visited and around 400 patients were treated.

\section{5 patients were evaluated}

Tinetti scale: the value increased from $15.79 \pm 8.13$ (T0) to $17.95 \pm 7.93$ (T1) for an average percentage variation of $15.16 \%(\mathrm{p} \leq 0.01)$ (Figure 1a). VAS scale: the value decreased from $6 \pm 2.46$ (T0) to $3.89 \pm 2.18$

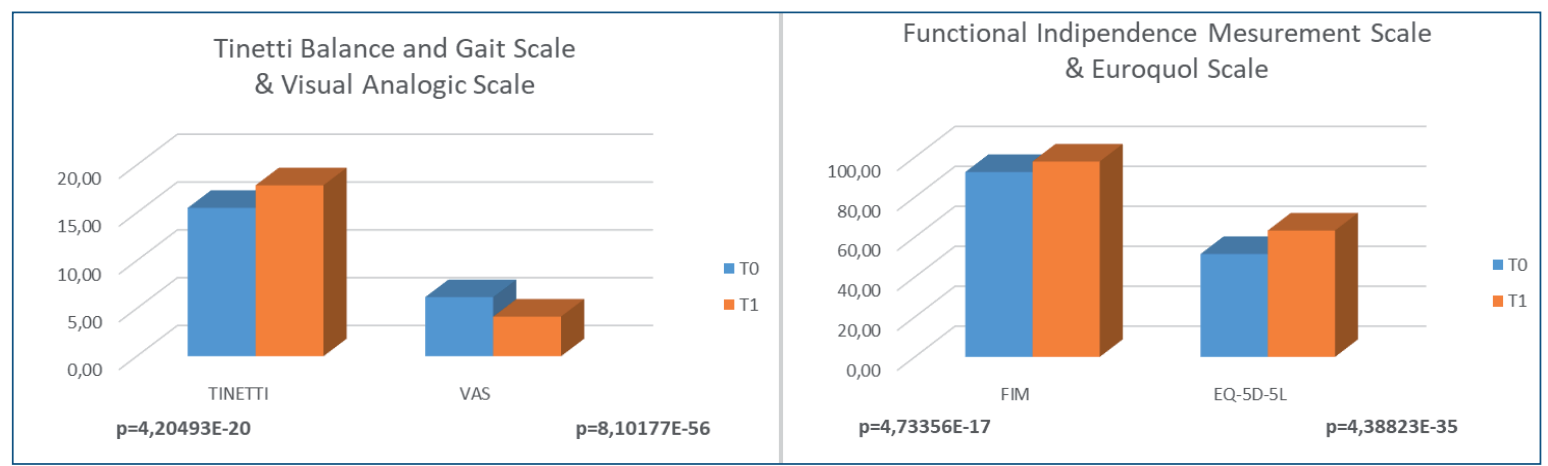

Fig. 1a, 1b - Tinetti, VAS, FIM and Euroqol scales relative to the total of 235 patients examined. 


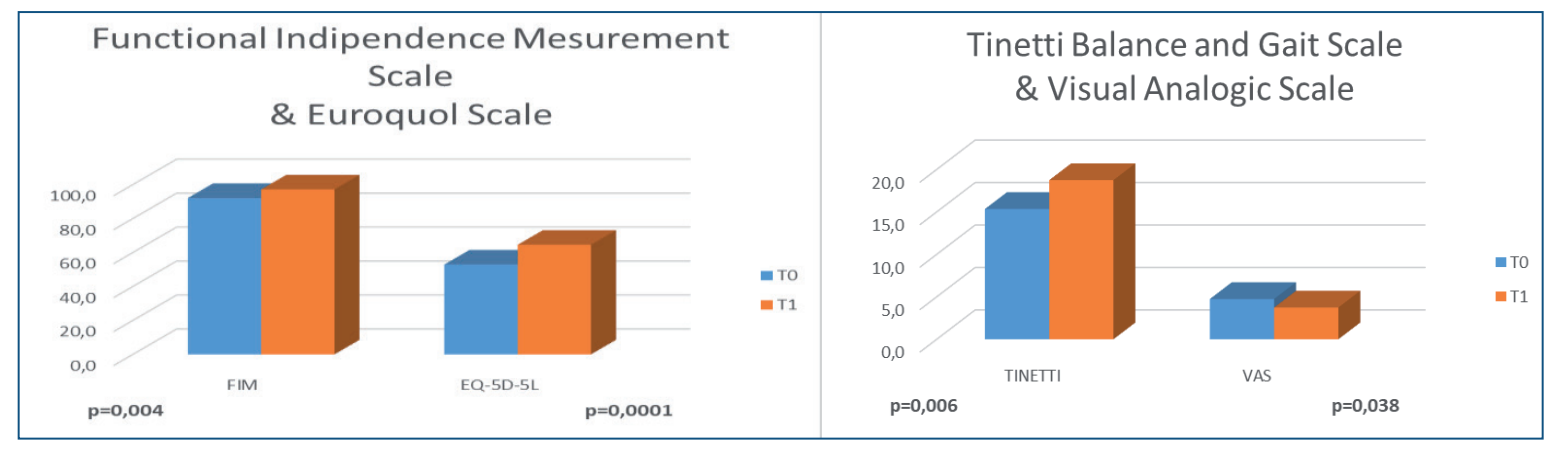

Fig. 2a, 2b - FIM, Euroqol, Tinetti and VAS scales relative to 15 patients affected by rare pathologies.

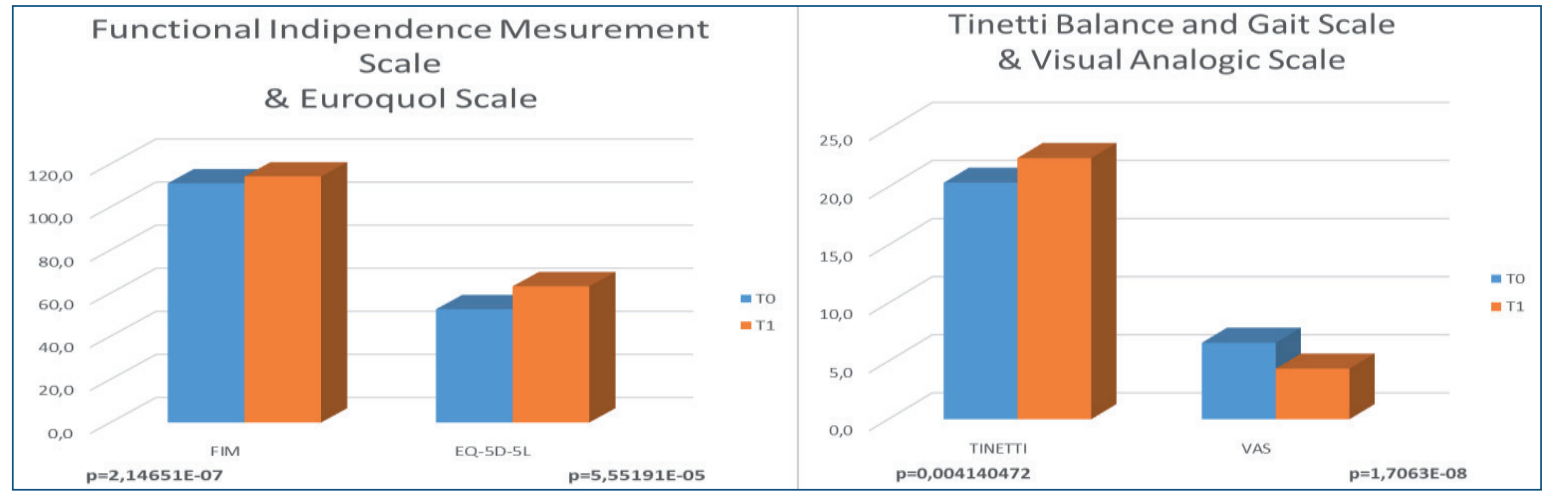

Fig. 3a, 3b - FIM, Euroqol, Tinetti and VAS scales relative to 50 cancer survivors.

(T1) for an average percentage variation of $35.16 \%$ ( $\mathrm{p} \leq 0.01$ ) (Figure 1a). FIM scale: the value increased from $94.10 \pm 25.40$ (T0) to $98.75 \pm 24.80$ (T1) for an average percentage variation of $4.94 \%(\mathrm{p} \leq 0.01)$ (Figure 1b). Euroqol scale: the value increased from $50.71 \pm 17.91$ (T0) to $62.76 \pm 16.92$ (T1) for an average percentage change of $23.74 \%(p \leq 0.01)$ (Figure 1b).

15 patients suffering from rare diseases including: Pallister-Killian syndrome, Steinheart syndrome, Martin Bell syndrome, Hangelman syndrome

Tinetti scale: the value increased from $14.8 \pm 7.1$ (T0) to $18.2 \pm 7.2$ (T1) for an average percentage variation of $23.23 \%(\mathrm{p} \leq 0.01)$ (Figure $2 \mathrm{~b})$. VAS scale: the value decreased from $5 \pm 2.8$ (T0) to $3.7 \pm 2.3$ (T1) for an average percentage variation of $25 \%$ (p $\leq 0.01$ ) (Figure $2 \mathrm{~b}$ ). FIM scale: the value increased from $85.6 \pm 27.4$ (T0) to $91.5 \pm 27$ (T1) for an average percentage variation of $6.9 \%(\mathrm{p} \leq 0.01)$ (Figure $2 \mathrm{a})$. Euroqol scale: the value increased from $48.7 \pm 9.9$ (T0) to $59.8 \pm 11$ (T1) for an average percentage variation of $22.8 \%(\mathrm{p} \leq 0.01)$ (Figure $2 \mathrm{a})$.

50 cancer survivors, suffering from disabilities mainly secondary to breast cancer

Tinetti scale: the value increased from $21.7 \pm 5.8$ (T0) to $23.3 \pm 5.2$ (T1) for an average percentage variation of $7.5 \%(\mathrm{p} \leq 0.05)$ (Figure $3 \mathrm{~b})$. VAS scale: the value decreased from $6.2 \pm 2.8$ (T0) to $4.2 \pm 2.1$ (T1) for an average percentage variation of $31.4 \%(\mathrm{p} \leq 0.01)$ (Figure 3b). FIM scale: the value increased from $114.6 \pm 14.5$ (T0) to $117.4 \pm 12.6$ (T1) for an average percentage variation of $2.41 \%(\mathrm{p} \leq 0.01)$ (Figure $3 \mathrm{a})$. Euroqol scale: the value increased from 57.2 \pm 17.9 (T0) to $66.8 \pm 16.2$ (T1) for an average percentage change of $16.9 \%(p \leq 0.01)$ (Figure $3 a)$. An average increase in peak expiratory flow (PEF) was observed, the value increased from $4.36 \pm 1.85(63.69 \%$ of the predictive value) from T0 to $4.84 \pm 1.90(71.98 \%$ of predictive value) at $\mathrm{T} 1$ with $(\mathrm{p} \leq 0.05)$ (Figure $3 \mathrm{c})$. An average increase in forced vital capacity (FVC) was observed from $2.3 \pm 1$ (T0) to $2.45 \pm 1.21$ (T1) with (p $\leq 0.05)$. An average increase in maximum expiratory volume was observed in the first second (FEV1 from $2.14 \pm 0.93$ (T0) to $2.26 \pm 0.92$ (T1) with $(\mathrm{p} \leq 0.05)$.

\section{5 patients with disabilities secondary to mental retardation (Mini-Mental State Examination, or $M M S E>18)$}

Tinetti scale: the value increased from $18.7 \pm 7.4$ (T0) to $20.5 \pm 6.5$ (T1) for an average percentage variation of $9.5 \%(p \leq 0.05)$ (Figure $4 b)$. VAS scale: the value decreased from $5.1 \pm 2.2(\mathrm{~T} 0)$ to $3.1 \pm 1.7(\mathrm{~T} 1)$ for an average percentage variation of $39.4 \%(p$ $\leq 0.01$ ) (Figure 4b). FIM scale: the value increased from 92.68 \pm 24.4 (T0) to 96.9 \pm 23.6 (T1) for an average percentage variation of $4.53 \%$ (p $\leq 0.01) \quad$ (Figure 4a). Euroqol scale: the value increased from $53.4 \pm 17.1$ (T0) to $63.8 \pm 16.8$ (T1) for an average percentage change of $19.5 \% \quad(p \leq 0.01)$

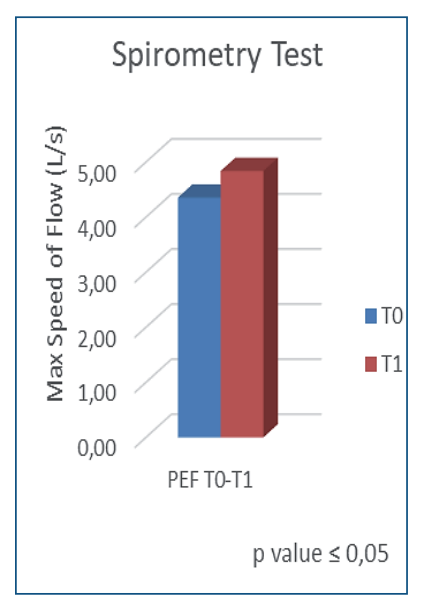

Fig. 3c - Spirometry Test relative to 50 cancer survivors. 


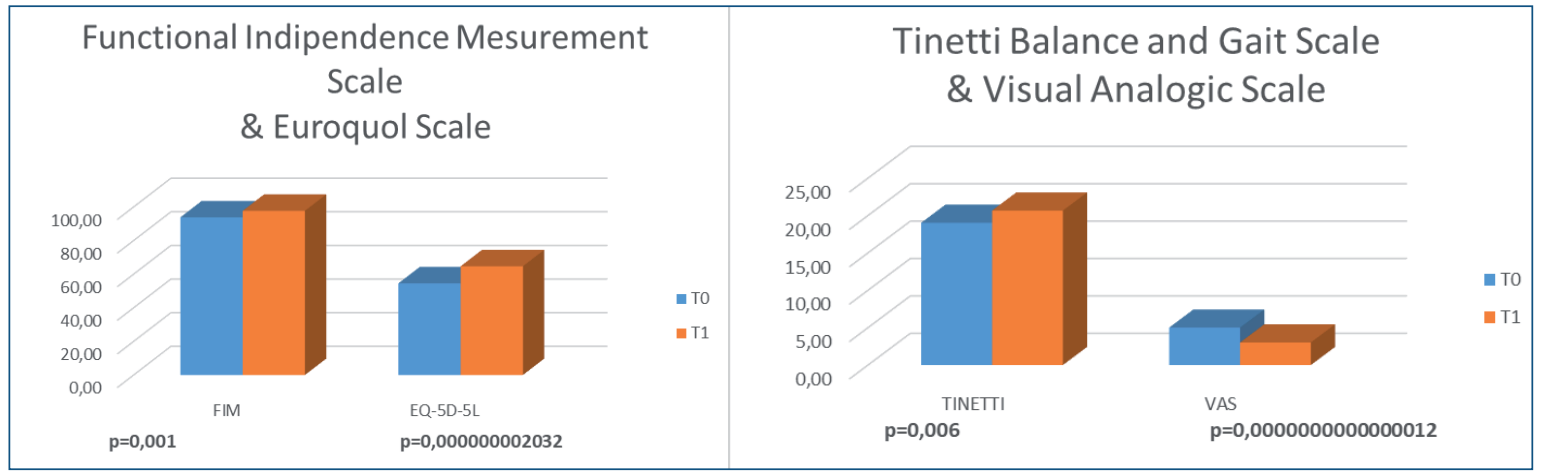

Fig. 4a, 4b - FIM, Euroqol, Tinetti and VAS scales relative to 75 patients affected by mental retardation.

(Figure 4a).

\section{0 patients with osteoarticular disabilities}

Tinetti scale: the value increased from $17.1 \pm 7$ (T0) to $19.6 \pm 6.6$ (T1) for an average percentage variation of $14.5 \%(\mathrm{p} \leq 0.05)$ (Figure $5 \mathrm{~b})$. VAS scale: the value decreased from $7.1 \pm 2.25$ (T0) to $4.9 \pm 2.20$ (T1) for an average percentage variation of $30.9 \%(\mathrm{p} \leq 0.01)$ (Figure 5b). FIM scale: the value increased from $105.4 \pm 18.4$ (T0) to $110.1 \pm 17.2$ (T1) for an average percentage variation of $4.5 \%(p \leq 0.01)$ (Figure $5 a)$. Euroqol scale: the value increased from $51.6 \pm 21.8$ (T0) to $64.3 \pm 17.8$ (T1) for an average percentage variation of $24.5 \%(\mathrm{p} \leq 0.01)$ (Figure $5 \mathrm{a})$.

\section{5 patients with disabilities secondary to $P C I$}

Tinetti scale: the value increased from $6.5 \pm 8.25$ (T0) to $7.6 \pm 8.9$ (T1) for an average percentage change of $16.8 \%(p \leq 0.05)$ (Figure $6 b)$. VAS scale: the value decreased from $5.7 \pm 2.8$ (T0) to $4.1 \pm 2.9$ (T1) for an average percentage variation of $27.2 \%(\mathrm{p} \leq 0.01)$ (Figure 6b). FIM scale: the value increased from
$73.32 \pm 26.8$ (T0) to $79.2 \pm 25.8$ (T1) for an average percentage variation of $8.1 \%(\mathrm{p} \leq 0.01)$ (Figure 6a). Euroqol scale: the value increased from $49.6 \pm 18$ (T0) to $64.6 \pm 15.8$ (T1) for an average percentage variation of $30.2 \%(\mathrm{p} \leq 0.01)$ (Figure $6 \mathrm{a})$.

\section{Patients with disabilities secondary to heart} disease

Tinetti scale: the value increased from $16.6 \pm 7.2$ (T0) to $20.1 \pm 6.1$ (T1) for an average percentage variation of $20.7 \%(p \leq 0.05)$ (Figure $7 b)$. VAS scale: the value decreased from $7.8 \pm 1.8$ (T0) to $5.3 \pm 1.8$ (T1) for an average percentage variation of $32 \%(\mathrm{p} \leq 0.01)$ (Figure 7b). FIM scale: the value increased from $109.5 \pm 12.8$ (T0) to $113.7 \pm 11.5$ (T1) for an average percentage variation of $3.9 \%(p \leq 0.01)$ (Figure $7 a)$. Euroqol scale: the value increased from $57.5 \pm 13.6$ (T0) to $70.4 \pm 17.8$ (T1) for an average percentage variation of $22.4 \%(\mathrm{p} \leq 0.01)$ (Figure $7 \mathrm{a})$.

25 Patients with disabilities secondary to ischemic or hemorrhagic stroke

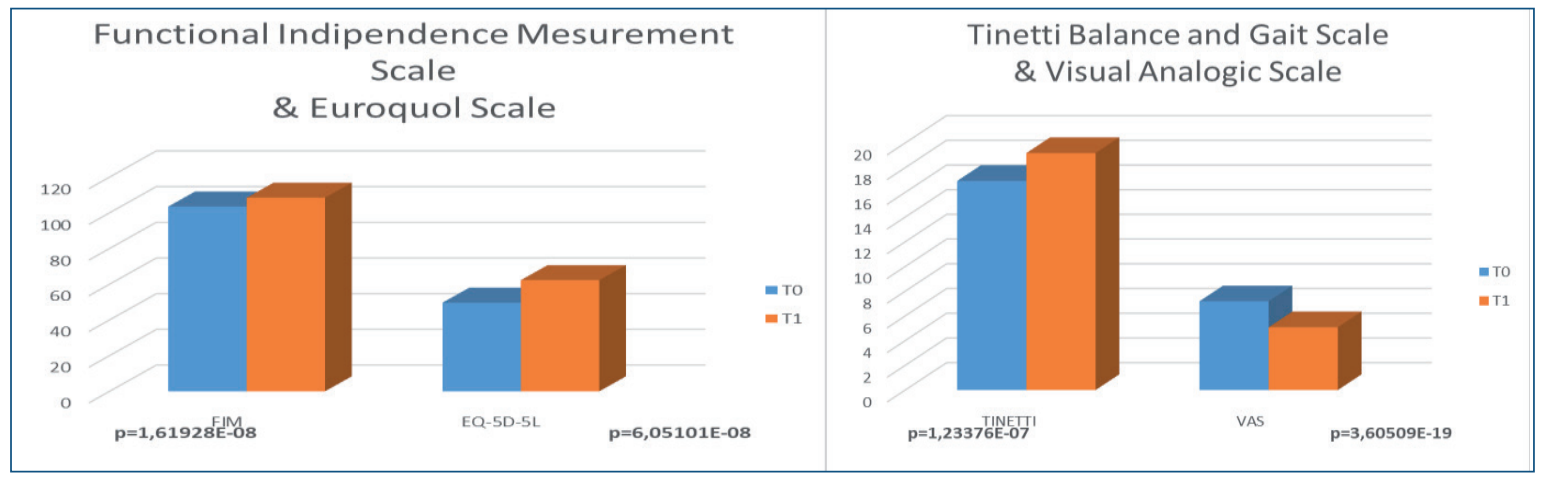

Fig. 5a, 5b - FIM , Euroqol, Tinetti and VAS scales relative to 30 patients affected by osteoarticular disabilities.

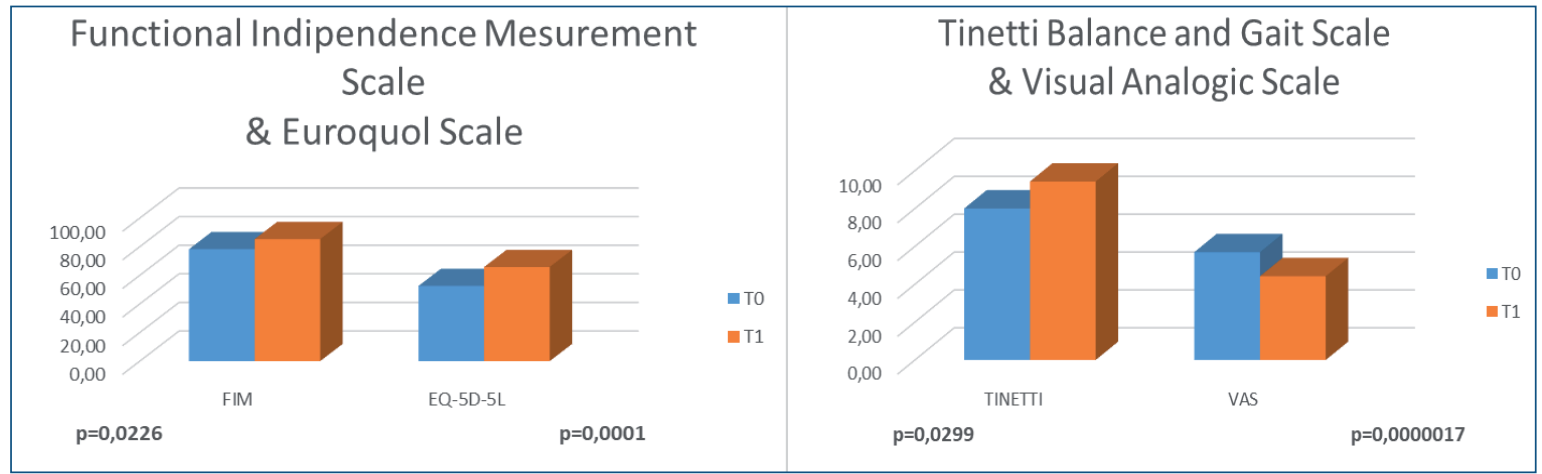

Fig. 6a, 6b - FIM, Euroqol, Tinetti and VAS scales relative to 25 patients affected by Infant Cerebral Palsy. 


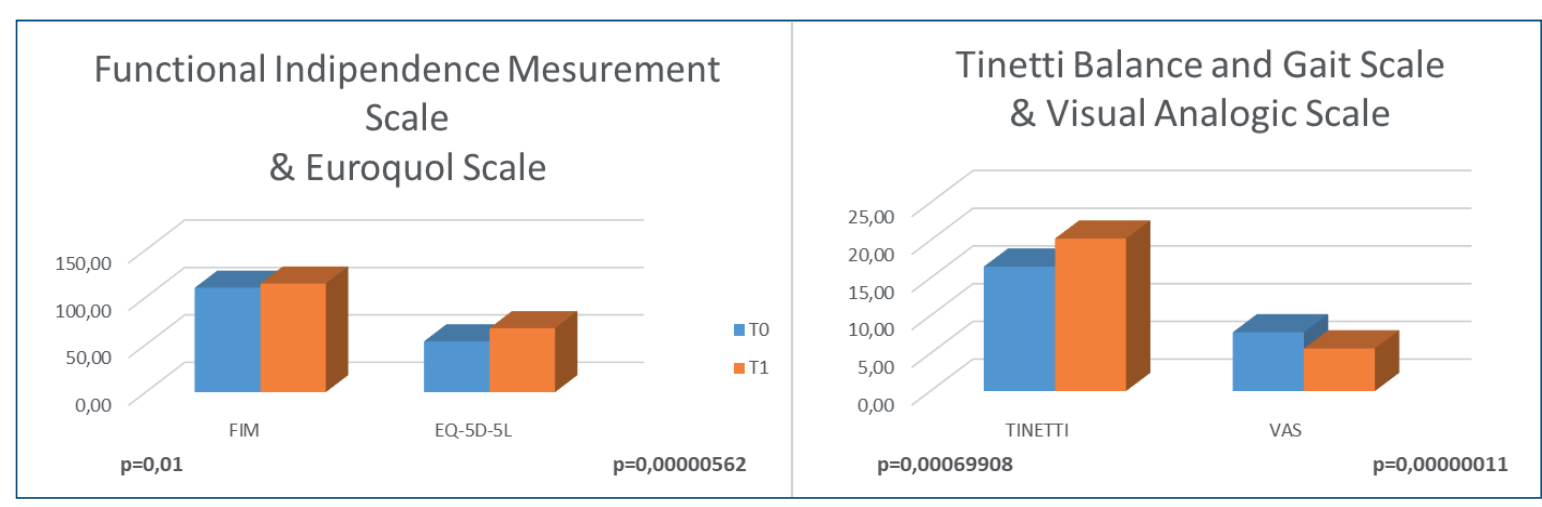

Fig. 7a, 7b - FIM, Euroqol, Tinetti and VAS scales relative to 15 patients affected by heart diseases.

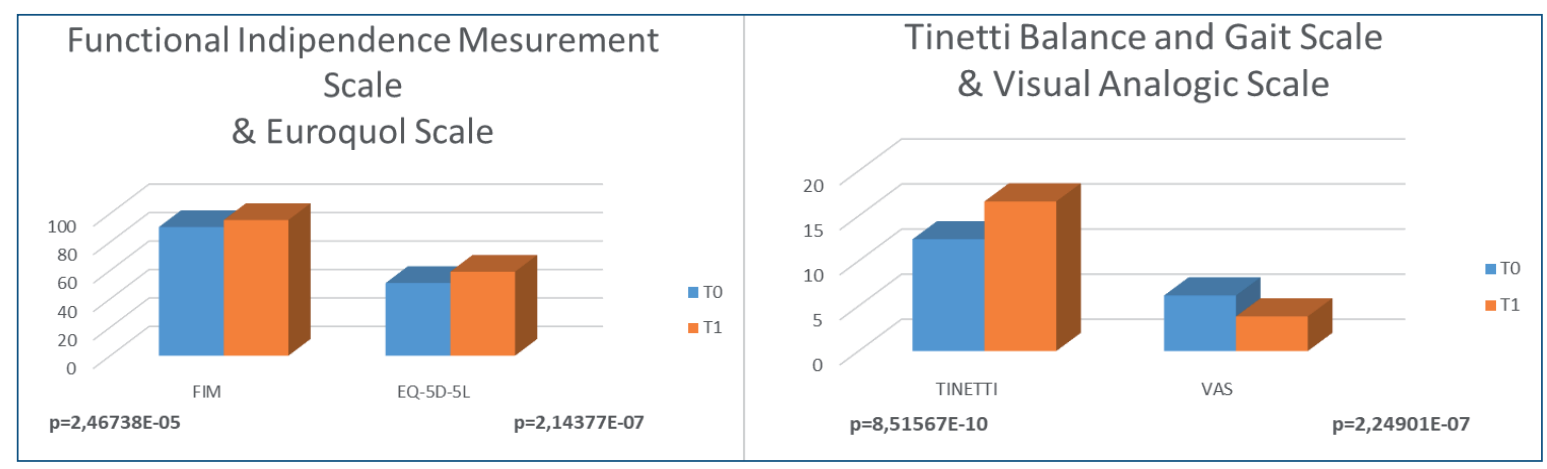

Fig. 8a, 8b - FIM, Euroqol, Tinetti and VAS scales relative to 25 patients affected by stroke consequences.

Tinetti scale: the value increased from $12.7 \pm 5.25$ (T0) to $16.9 \pm 5.4$ (T1) for an average percentage change of $32.7 \%(\mathrm{p} \leq 0.05)$ (Figure $8 \mathrm{~b})$. VAS scale: the value decreased from $5.9 \pm 1.8$ (T0) to $3.5 \pm 2.1$ (T1) for an average percentage variation of $31.4 \%$ (p $\leq 0.01$ ) (Figure $8 \mathrm{~b}$ ). FIM scale: the value increased from $96.8 \pm 21.4(\mathrm{~T} 0)$ to $101.5 \pm 20.5(\mathrm{~T} 1)$ for an average percentage variation of $40.7 \%(\mathrm{p} \leq 0.01)$ (Figure 8a). Euroqol scale: the value increased from $47.3 \pm 16.7$ (T0) to $56.7 \pm 14.9$ (T1) for an average percentage variation of $20.1 \%(\mathrm{p} \leq 0.01)$ (Figure $8 \mathrm{a})$.

\section{DISCUSSIONS}

The common site of the dysfunction, despite the diversity of the bowel or the affected somatic structure, is in part due to the phenomenon of viscerovisceral or viscero-somatic convergence in the central nervous system, for which fibers afferent from multiple internal organs belong to the SAME sensory neurons (Cervero, 2014).

In the referred pain with hyperalgesia, additional stimuli exerted on the somatic tissues in the algogenic reference areas, for example a painful compression on the skeletal muscle, determine a more intense algic symptomatology (hyperalgesia). If the dysfunctional process has been particularly intense and / or long lasting, even normally non-harmful stimulations applied to the skin are capable of causing pain (allodynia). The treatment of the reference area of sensation usually changes the subjective and objective symptomatology, reducing its intensity and sometimes determining its disappearance.

Numerous studies have been conducted in the clinic to characterize the phenomenon of referred pain in various visceral pathologies (ischemic heart disease, biliary and urinary colic, dysmenorrhea
/ endometriosis, chronic pelvic pain, irritable bowel syndrome) through the measurement of pain thresholds at various stimuli (thermal, electrical, mechanical) of the wall tissues (skin, subcutis and muscle) in the reference area of sensation (Cervero, 2009).

The presence of hyperalgesia was detected in terms of lowering the threshold itself compared to the values recorded in the same locations in normal subjects. The complex of these studies revealed that hyperalgesia or distant dysfunction is mainly a muscle phenomenon (subcutaneous / skin tissues are affected in the case of dysfunctional processes of particular entity), it manifests itself early, already after the first visceral dysfunctional episodes, and is accentuated with the repetition of these.

It also tends to be a long-lasting phenomenon, which persists after the cessation of spontaneous pain and sometimes persists even after the removal of the primitive visceral outbreak that generated it.

Thermal Medicine today more than ever can represent a great opportunity for intervention in the field of viscero-somatic stimulation and vice versa and these approaches, suitably integrated and administered by customizing them to individual needs, as evidenced by the preliminary data presented, affect the inflammatory processes in general, on the cerebral plasticity of the motor reorganization, automatically stimulating a global motor control on the dysfunctional limbs and the healthy limbs, through a global kinesthetic sensory conditioning.

Considering the scientific bases and the results obtained, we can affirm that the CIT, the Integrated Thermal Care program can represent a real opportunity to intervene in the somatic viscous reflex mechanisms and vice versa through a unique integrated stimulation for patients suffering from sensorineural disabilities. 


\section{REFERENCES}

1. Barassi, G., Bellomo, R. G., Di Giulio, C., Giannuzzo, G., Irace, G., Barbato, C., \& Saggini, R. (2018). Effects of manual somatic stimulation on the autonomic nervous system and posture. In Progress in Medical Research (pp. 97109). Springer, Cham.

2. Barassi, G., Bellomo, R. G., Porreca, A., Di Felice, P. A., Prosperi, L., \& Saggini, R. (2018). Somato-visceral effects in the treatment of dysmenorrhea: neuromuscular manual therapy and standard pharmacological treatment. The Journal of Alternative and Complementary Medicine, 24(3), 291-299.

3. Barassi, G., Bellomo, R. G., Porreca, A., Giannuzzo, G., Irace, G., Trivisano, L., \& Saggini, R. (2018). Rehabilitation of neuromotor disabilities in aquatic microgravity environment. In Respiratory Ailments in Context (pp. 61-73). Springer, Cham.

4. Barassi, G., Obrero-Gaitan, E., Irace, G., Crudeli, M., Campobasso, G., Palano, et al. (2020). Integrated Thermal Rehabilitation: A New Therapeutic Approach for Disabilities. Adv Exp Med Biol.,1251:29-38.

5. Cervero, F. (2009). Spinal cord hyperexcitability and its role in pain and hyperalgesia. Experimental Brain Research, $196(1), 129-137$

6. Cervero, F. (2014). Central sensitization and visceral hypersensitivity: Facts and fictions. Scandinavian Journal of Pain, 5(2), 49-50.

7. Diot, P. (1995). Aerosols in Medicine: Principles, Diagnosis, and Therapy. Chest, 108(5), 16-17.

8. Gianfaldoni, S., Tchernev, G., Wollina, U., Roccia, M. G., Fioranelli, M., Gianfaldoni, R., \& Lotti, T. (2017). History of the Baths and Thermal Medicine. Open Access Macedonian Journal of Medical Sciences, 5(4), 566.

9. Jackson, R. (1990). Waters and spas in the classical world. Medical History, 34(S10), 1-13.

10. Laird, J. M., \& Cervero, F. (2011). Looking at visceral pain: New vistas. Scandinavian Journal of Pain, 2(3), 93-94. 